\title{
FONTES PROTÉICAS SOBRE O DESEMPENHO DE TERNEIROS CONFINADOS ${ }^{1}$
}

\author{
PROTEIN SOURCES UPON PERFORMANCE \\ OF CONFINED CALVES
}

\section{Luis Fernando Vilani de Pelegrini ${ }^{2}$ Cleber Cassol Pires $^{3}$ João Restle ${ }^{4}$}

\section{RESUMO}

O presente trabalho foi conduzido no período de 14 de julho a 06 de outubro de 1992, nas dependências do Departamento de Zootecnia da Universidade Federal de Santa Maria com o objetivo de avaliar o efeito de duas fontes protéicas (grão de soja vs farelo de soja) sobre o desempenho de terneiros de corte em confinamento. $O$ período experimental teve duracão de 84 dias, subdivididos em quatro períodos de 21 dias. Foram utilizados 20 terneiros inteiros cruza Nelore $x$ Charolês, com média de peso inicial de $160 \mathrm{~kg}$ e média de idade de 7 meses, distribuídos em quatro piquetes com $800 \mathrm{~m}^{2}$ cada um. Os animais foram submetidos aos seguintes tratamentos: T1 - silagem de sorgo mais concentrado (farelo de soja + milho + mistura mineral), e T2 - silagem de sorgo mais concentrado (soja grão + milho + mistura mineral). O grão de soja foi utilizado in natura e triturado no momento do preparo da ração. As proporções de volumoso : concentrado utilizadas no experimento foram de: 75,04 : 24,96; 71,04 : 28,96; 67,53 : 32,47 e 62,72 : 37,28, no $1^{\text {o }}$ $2^{-}, 3^{o}$ e $4^{o}$ períodos, respectivamente. As dietas foram isoprotéicas, contendo um teor médio de proteína bruta de $12,5 \%$ na matéria seca. Os resultados (média dos quatro períodos) para ganho de peso médio diário ( $\mathrm{kg} / \mathrm{an} / \mathrm{dia})$, consumo de matéria seca (kg/an/dia) e conversão alimentar para $T 1$ foram de $1,114 \mathrm{~kg}$; $6,03 \mathrm{~kg}$ e 5,55, respectivamente e, para 72 , foram de: $0,975 \mathrm{~kg}$; $5,69 \mathrm{~kg} 5,91$, respectivamente. Os animais submetidos ao T1 apresentaram maior ganho de peso médio diário $(P<0,05)$. Quando o consumo de matéria seca foi avaliado em $\mathrm{kg} / \mathrm{an} / \mathrm{dia}$, a análise de variância demonstrou diferença significativa entre os tratamentos $(P<0,05)$. No entanto, quando se avaliou o consumo de matéria seca por $100 \mathrm{~kg}$ de peso vivo e por unidade de tamanho metabólico, não ocorreu diferença significativa entre os mesmos $(P>0,05)$. Quanto à conversão alimentar, não houve diferença significativa $(P>0,05)$ entre os tratamentos.

Palavras-chave: confinamento, farelo de soja, soja grão, terneiros

\section{SUMMARY}

The present work was carried out from 07/14 to 10/06/92, at the Department of Animal Science "Universidade Federal de Santa Maria, RS, Brazil". The purpose was to evaluate the effect of two protein sources (soybean grain versus soybean meal) upon the performance of confined beef calves. The experimental period of 84 days, was subdivided into four periods of 21 days. Twenty noncastrated Nellore $x$ Charolais crossbred calves, with initial average weight of $160 \mathrm{~kg}$ and average age of 7 months, were used. The calves were distributed in four paddocks of $800 \mathrm{~m}^{2}$ each. The animals were submitted to the following treatments: $T 1$ - sorghum silage plus concentrate (soybean meal + corn + mineral mixture), and T2 - sorghum silage plus concentrate (soybean grain + corn + mineral mixture). The soybean grain was used in natura and triturated at the moment the ration was being prepared. The proportions of roughage : concentrate used in the experiment were: $75.04: 24.96 ; 71.04$ : 28.96; $67.53: 32.47$ and $62.72: 37.28$, in the $1^{\text {st }}, 2^{\text {nd }}, 3^{\text {rd }}$ and $4^{\text {th }}$ periods, respectively. The diets were isoprotein, with an average content of crude protein of $12.5 \%$ (in DM). The mean of the four periods for average daily weight gain (kg/an/day), dry matter consumption (kg/an/day) and feed conversion were $1.114 \mathrm{~kg}$; $6.03 \mathrm{~kg}$ and 5.55 for $\mathrm{T1}$ and $.975 \mathrm{~kg}, 5.69 \mathrm{~kg}$ and 5.91 for T2 respectively. The animals submitted to Tl showed a better average daily weight gain $(P<.05)$. The analysis of variance showed significant difference between the treatments for dry matter consumption ( $\mathrm{kg} / \mathrm{an} / \mathrm{day})$. However, when the consumption of dry matter was analysed per 100kg of live weight and per unity of metabolic size, there was no significant difference between T1 and $T 2(P>.05)$. Concerning feed conversion, there was no significant difference between the treatments $(P>.05)$.

Key words: calves, confinement, soybean grain, soybean meal.

\footnotetext{
${ }^{1}$ Parte da Dissertação de Mestrado do primeiro autor apresentada ao Curso de Pós-graduação em Zootecnia da Universidade Federal de Santa Maria (UFSM).

${ }^{2}$ Médico Veterinário, Mestre, autônomo.

${ }^{3}$ Médico Veterinário, Doutor, Professor Titular, Departamento de Zootecnia, UFSM, 97105-900, Santa Maria, RS. E-mail cpires@ccr.ufsm.br. Autor para correspondência.

${ }^{4}$ Engenheiro Agônomo, PhD., Professor Titular, Departamento de Zootecnia, UFSM. Pesquisador do CNPq.

Recebido para publicação em 02.06.98. Aprovado em 11.08.99
} 


\section{INTRODUÇÃO}

No Rio Grande do Sul, o desmame aos sete meses de idade dos terneiros de corte coincide com o período de outono/inverno. Os terneiros, que nesse período são mantidos em campo natural, apresentam baixo ganho, ou mesmo perda de peso, o que ocasiona o abate tardio dos mesmos. O arraçoamento pode ser uma boa alternativa de alimentação dos terneiros desmamados aos sete meses. No entanto, nesse sistema de alimentação, o concentrado geralmente é o componente com o qual o produtor se preocupa ao fazer a relação custo benefício, pois nem sempre possue os ingredientes necessários na sua propriedade ou no mercado consumidor mais próximo.

Segundo GUARAGNA et al. (1977), a soja-grão pode tornar-se uma fonte de proteína de baixo custo, quando produzida na própria fazenda ou em caso de superprodução no País. BOSE (1985), descrevendo concentrados e suplementos usuais para bovinos de corte em confinamento, indica as sementes de oleaginosas para utilização ocasional, em função do preço ou disponibilidade, devendo o seu fornecimento ser limitado a 2 ou $3 \mathrm{~kg}$ por animal por dia. O mesmo autor diz, ainda, que o grão de soja apresenta boa composição (40\% PB e $87 \%$ NDT) e afirma que as tortas ou farelos da extração de óleo são mais indicados, pois os cuidados para seu uso são menores.

A adição de lipídios na dieta para ruminantes pode provocar decréscimo na digestibilidade da fração fibrosa da dieta e alterações profundas no metabolismo ruminal. Numa revisão sobre o assunto, PALMQUIST (1989) observa que uma dieta rica em fibra é necessária para que se obtenham condições ótimas no rúmen, quando se deseja utilizar lipídios em quantidades acima daquelas, normalmente, encontradas em dietas para ruminantes, pois os ácidos graxos se associam às partículas de alimento no rúmen, diminuindo a ação dos microorganismos. O mesmo autor afirma que ocorre decréscimo da digestibilidade a nível de rúmen quando lipídios alcançam valores acima de 5 a $6 \%$ da dieta. Segundo ANDRIGUETTO et al. (1986), a adição de gorduras é bastante variável, podendo ir, em determinados casos até 10\%. BATISTA et al. (1983) afirmam que o grão de soja contém $23 \%$ de óleo. Segundo SILVA (1989), este valor oscila entre 15 e $21 \%$.

FERREIRA et al. (1983) utilizaram, em um experimento, cem novilhos com idade entre $20 \mathrm{e}$ 38 meses, com peso médio de $359 \mathrm{~kg}$, sendo 60 mestiços Holandês-Zebú e 40 pertencentes às raças Ne- lore e Gir. Os animais foram distribuídos em cinco currais segundo o critério de peso, idade e raça ou "grau de sangue" e avaliados durante 84 dias. Os tratamentos utilizados foram: 0\% (A); 5\% (B); $10 \%$ (C); 20 (D) de soja crua e 20\% (E) de soja tostada na dieta total. Os volumosos utilizados foram feno de Capim-Jaraguá e feno de soja perene. Os ingredientes do concentrado foram milho, soja crua, soja tostada e minerais. A dieta total foi constituída de volumoso:concentrado na proporção de 1:1 na matéria seca. Os ganhos médios diários por novilho foram de 1,$11 ; 1,14 ; 1,19 ; 1,21$ e $1,33 \mathrm{~kg}$ para os tratamentos A, B, C, D e E, respectivamente.VELLOSO et al. (1986), trabalhando com novilhos das raças Nelore (N), Gir (G), Caracu (C) e seus cruzamentos (NG, GN, NC, GC, CG), com 19 meses de idade e $275 \mathrm{~kg}$ de peso vivo, alimentados com $2 \mathrm{~kg}$ de grãos de soja (crus) moídos, $2 \mathrm{~kg}$ de rolão de milho e silagem de milho à vontade, verificaram ganho de peso médio diário de $1,206 \mathrm{~kg}$ por animal/dia.

O estado do Rio Grande do Sul é um grande produtor de soja. A utilização da mesma na alimentação animal, tanto na forma de grão como na forma de farelo, vai depender do preço das duas formas e do resultado no desempenho animal. É importante que sejam gerados mais dados sobre a resposta animal em frente as duas formas de utilização. Neste sentido, o presente experimento teve como objetivo avaliar o grão de soja no desempenho de terneiros de corte confinados.

\section{MATERIAL E MÉTODOS}

O experimento foi conduzido nas instalações do Setor de Bovinocultura de Corte do Departamento de Zootecnia da Universidade Federal de Santa Maria - UFSM, Rio Grande do Sul. Foram utilizados 20 terneiros não castrados cruza Charolês $\mathrm{x}$ Nelore, com média de peso inicial de $160 \mathrm{~kg}$ e média de idade de 7 meses, oriundos de uma propriedade particular localizada no município de São Martinho da Serra, onde, no período pré-desmama, vacas e terneiros foram mantidos em campo nativo. No início do experimento, os mesmos foram distribuídos em quatro piquetes a céu aberto de $800 \mathrm{~m}^{2}$ cada um, segundo um delineamento inteiramente casualizado. Os terneiros foram divididos aleatoriamente e submetidos aos seguintes tratamentos: T1 Silagem de sorgo mais concentrado (milho em grão + farelo de soja + mistura mineral) e T2 - Silagem de sorgo mais concentrado (milho em grão + soja em grão + mistura mineral). As dietas foram calculadas segundo as normas do NRC (1984), para ganho de $1 \mathrm{~kg} / \mathrm{an} / \mathrm{dia}$, sendo isoprotéicas, com teor médio de $12,55 \%$ de proteína bruta. 
O experimento teve a duração de 84 dias, subdivididos em quatro períodos de 21 dias. Antecedendo o período experimental os animais foram adaptados à dieta e nas instalações durante doze dias. As proporções de volumoso : concentrado estão apresentadas na tabela 1 . As proporções de cada ingrediente do concentrado são apresentadas na tabela 2. A alimentação era fornecida ad libitum duas vezes ao dia, em partes iguais, às 8 horas e às 17 horas. $\mathrm{O}$ volumoso era distribuído nos comedouros e sobre o mesmo colocava-se o concentrado; após, era realizada a mistura de ambos. Pela manhã, antes de fornecer o alimento, eram pesadas as sobras do dia anterior e anotadas em uma planilha de campo para se obter o consumo do dia anterior. Ajustavam-se, caso necessário, as quantidades tomando-se como referência uma sobra em torno de $10 \%$ do oferecido. Para o consumo de Matéria Seca e Conversão Alimentar, cada lote de cinco animais foi considerado uma unidade experimental; já para o ganho de peso médio diário, cada animal foi considerado uma unidade experimental. Semanalmente, foram coletadas amostras dos alimentos oferecidos e das sobras, tendo as amostras passado por uma présecagem em estufa ventilada a $65^{\circ} \mathrm{C}$ e submetidas, posteriormente, à secagem definitiva. As pesagens dos animais foram feitas no início do experimento e após cada 21 dias até o final do mesmo, com jejum de sólidos de doze horas. Pela técnica de TILLEY \& TERRY (1963), fez-se a digestibilidade in vitro da matéria seca (DIVMS \%) e da matéria orgânica (DIVMO \%) das silagens oferecidas e dos ingredientes que constituíram os concentrados. Foi utilizado o Delineamento Inteiramente casualizado em que o modelo matemático adotado foi $\mathrm{Yij}=\mathrm{u}+\mathrm{ti}+\sum \mathrm{ij}$. Os dados foram submetidos à análise de variância utilizando-se o programa SAS (1990).

\section{RESULTADOS E DISCUSSÃO}

Os dados referentes à análise bromatológica dos ingredientes utilizados nas dietas experimentais estão apresentados na tabela 3. As médias

Tabela 1 - Proporções de volumoso:concentrado utilizadas no experimento (considerando o período de 21 dias).

\begin{tabular}{|c|c|c|c|c|}
\hline \multirow[t]{2}{*}{ Ingrediente } & \multicolumn{4}{|c|}{ Períodos (21dias) } \\
\hline & $1^{\mathrm{o}}$ & $2^{\underline{o}}$ & $3^{\mathrm{o}}$ & $4^{\circ}$ \\
\hline Volumoso & 75,04 & 71,04 & 67,53 & 62,72 \\
\hline Concentrado & 24,96 & 28,96 & 32,47 & 37,28 \\
\hline
\end{tabular}

Tabela 2 - Proporções, em cada período, dos ingredientes do concentrado nos tratamentos 1 e 2 ( $\%$ da MS)

\begin{tabular}{|c|c|c|c|c|}
\hline \multirow[t]{2}{*}{ INGREDIENTE } & \multicolumn{4}{|c|}{ PERÍODOS (21 dias) } \\
\hline & $1^{\mathrm{o}}$ & $2^{\mathrm{o}}$ & $3^{-}$ & $4^{\mathrm{o}}$ \\
\hline \multicolumn{5}{|l|}{ Tratamento 1} \\
\hline Milho & 38,0 & 46,0 & 66,0 & 67,0 \\
\hline Farelo de soja & 58,0 & 50,0 & 30,5 & 30,0 \\
\hline Farinha de ossos & 3,6 & 3,4 & 3,0 & 2,5 \\
\hline Sal comum & 0,4 & 0,6 & 0,5 & 0,5 \\
\hline \multicolumn{5}{|l|}{ Tratamento 2} \\
\hline Milho & 32,0 & 40,0 & 63,0 & 65,0 \\
\hline Soja grão & 64,0 & 56,0 & 33,5 & 32,0 \\
\hline Farinha de ossos & 3,6 & 3,4 & 3,0 & 2,4 \\
\hline Sal comum & 0,4 & 0,6 & 0,5 & 0,6 \\
\hline
\end{tabular}

de ganho de peso diário, ganho de peso total e peso inicial e final, consumo de matéria seca e conversão alimentar de cada tratamento são apresentadas na tabela 4. Pela análise de variância, foi constatado que houve diferença $(\mathrm{P}<0,05)$ para a variável ganho de peso médio diário. Os terneiros tiveram ganho de peso médio diário superior aos encontrados por GOMIDE et al. $(1977 ; 0,693 \mathrm{~kg})$, que confinaram novilhos com 18 a 20 meses, alimentados com $12 \mathrm{~kg}$ de silagem de milho, $0,75 \mathrm{~kg}$ de farelo de algodão e $0,95 \mathrm{~kg}$ de soja moída por animal/dia; e por OBEID \& GOMIDE (1979; 0,71kg), que trabalharam com novilhos de 20 meses de idade, utilizando silagem de milho, fubá de milho e soja grão triturado.

No presente trabalho, os animais submetidos ao T1 apresentaram ganho de peso médio diário $12,47 \%$ superior aos animais do T2. Esse fato pode ser em razão da menor degradabilidade ruminal da proteína do farelo de soja em relação à soja grão, já que as digestibilidades in vitro para as rações do $\mathrm{T} 1$ $(65,45 \%)$ e T2 $(63,72 \%)$ foram próximas. Os animais que receberam a fonte protéica farelo de soja (T1), apresentaram maior consumo de matéria seca $(\mathrm{P}<0,05) \mathrm{em} \mathrm{kg/animal/dia).} \mathrm{Quando} \mathrm{se} \mathrm{comparou}$ o consumo por $100 \mathrm{~kg}$ de peso vivo e por unidade de tamanho metabólico, não foi constatada diferença entre os tratamentos $(\mathrm{P}>0,05)$. Isso pode ser explicado pelo fato de que os animais submetidos ao T1 apresentaram maior ganho de peso diário e, consequentemente, foram mais pesados no decorrer do experimento. Portanto, pode ter ocorrido confundimento do consumo de matéria seca com o peso dos animais, pois quando se anula esse efeito, não ocorre diferença entre os tratamentos, conforme mostra a tabela 4. O consumo não foi influenciado pelas di- 
Tabela 3 - Teores médios de matéria seca (MS) e proteína bruta (PB) dos ingredientes utilizados no experimento.

\begin{tabular}{lcc}
\hline INGREDIENTES & MS (\%) & PB (\%)* \\
& & \\
\hline Silagem de sorgo & 32,85 & 8,09 \\
Farelo de soja & 89,50 & 56,55 \\
Soja grão & 91,04 & 41,27 \\
Milho & 88,66 & 11,41 \\
& & \\
\hline
\end{tabular}

ferenças nos coeficientes de digestibilidade da MS, que foram de 65,29 para T1 e 64,37 para T2, bem como da MO, que foram de 65,45 para $\mathrm{T} 1$ e 63,72 para T2.

Resultados contrários a esses foram obtidos por MARTINEZ et al. (1981), que observaram decréscimo no consumo de matéria seca, quando utilizaram dois níveis de óleo (4\% e $8 \%$ ) comparados com a ausência de óleo na ração. Segundo o NRC (1984), os níveis de gordura nas rações para ruminantes variam de 2 a $5 \%$ e níveis mais altos tendem a reduzir o consumo. No presente trabalho, o teor médio de óleo nas rações contendo soja grão foi de $2,7 \%$, o qual não foi suficiente para que os animais alimentados com ração contendo soja grão apresentassem menor consumo em relação àqueles alimentados com ração sem soja grão. Isso está de acordo também com VIEIRA et al (1981), que afirmam que os bovinos não toleram muito bem rações cujo nível de óleo exceda $4 \%$.

A análise de variância para conversão alimentar não revelou diferença significativa $(\mathrm{P}>0,05)$ entre os dois tratamentos. Os terneiros deste experimento apresentaram conversão alimentar

Tabela 4 - Peso inicial e final, ganho de peso médio diário e total, consumo médio diário de matéria seca (kg/animal/dia), $\mathrm{kg}$ por $100 \mathrm{~kg}$ de peso vivo $(\mathrm{kg} / 100 \mathrm{kgPV} / \mathrm{dia})$, gramas por unidade de tamanho metabólico (g/UTM/dia) e conversão alimentar de acordo com o tratamento.

\begin{tabular}{lcc}
\hline Parâmetros & $\begin{array}{c}\text { T1 } \\
\text { farelo de soja }\end{array}$ & $\begin{array}{c}\text { T2 } \\
\text { soja grão }\end{array}$ \\
& & \\
\hline & & \\
Peso vivo inicial $(\mathrm{kg})$ & 160,90 & 161,00 \\
Peso vivo final $(\mathrm{kg})$ & 254,50 & 242,90 \\
Ganho de peso diário (kg)* & 1,11 & 0,97 \\
Ganho de peso total $(\mathrm{kg})$ & 93,60 & 81,90 \\
CMS (kg/animal/dia)* & 6,03 & 5,69 \\
CMS (kg/100kg PV)** & 2,90 & 2,81 \\
CMS (g/UTM/dia)** & 110,21 & 106,21 \\
Conversão alimentar** & 5,55 & 5,59 \\
& & \\
\hline
\end{tabular}

$*(\mathrm{P}<0,05)$.

$* *(\mathrm{P}>0,05)$ melhores em relação aos resultados obtidos por TOWNSEND $(1991 ; 4,70)$ e RESTLE \& ALVES FILHO $(1992 ; 4,82)$. No entanto foram próximos aos resultados obtidos por QUADROS et al. (1990; 4,90); PILAR (1993; 5,39) e HENRIQUE et al. (1992; 5,72), os quais confinaram terneiros de corte na mesma faixa etária.

\section{CONCLUSÕES}

A utilização de farelo de soja como fonte protéica proporciona maior ganho de peso médio diário em relação à soja grão, no entanto, a mesma se constitui numa boa alternativa como fonte protéica para bovinos em confinamento.

\section{REFERÊNCIAS BIBLIOGRÁFICAS}

ANDRIGUETTO, J.M., PERRY, L., MINARDI, I. $\boldsymbol{e} \boldsymbol{t} \boldsymbol{a l}$. Nutrição animal. 4 ed. São Paulo: Nobel, 1986. V.1. 395p.

BATISTA, A.M.V., SILVA, J.F.C. da, GARCIA, J.A. $\boldsymbol{e} \boldsymbol{t} \boldsymbol{a l}$. Digestões total e parcial em novilhos alimentados com rações contendo soja tratada com formaldeído e duas proporções volumoso : concentrado. Rev Soc Bras Zootec, Viçosa, v.4, n.12, p.667-681, 1983 .

BOSE, M.L.V. Concentrados e suplementos usuais para bovinos de corte em confinamento. In: CURSO DE ATUALIZAÇÃO EM CONFINAMENTO DE BOVINOS DE CORTE, 1985, Piracicaba, SP. Anais... Piracicaba : FEALQ, 1985. 84p. p.37-46.

FERREIRA, J.J., REH FELD, O.A.M., AZEVEDO, N.A. Efeito do uso de soja tostada e diferentes níveis de soja crua no desenvolvimento de novilhos confinados. In: REUNIÃO ANUAL DA SOC. BRAS. ZOOTEC., 20, Pelotas, 11-16 Jul. 1983. Anais... Viçosa, Soc. Bras. Zootec., 1983, p. 132, 463 p.

GOMIDE, J.A., OBEID, J.A., PAULA, R.R. Fontes e níveis de energia e de proteína na alimentação de novilhos em confinamento. Rev Ceres, Viçosa, v.24, n.133, p.297-305, 1977.

GUARAGNA, G.P., CARRIEL, J.M., FIGUEIREDO, A.L. Efeito da soja grão moída no crescimento de novilhas leiteiras. Bol Ind An, Nova Odessa, v.34, n.1, p.69-73, jan/jun, 1977.

HENRIQUE, W., LEME, P.R., JUSTO, C.L. et al. Uso da silagem de milho ou de capim elefante e da sacharina como substituto parcial do concentrado, na engorda de bovinos em confinamento. In: REUNIÃO ANUAL DA SOC. BRAS. ZOOTEC, 29, 1992, Lavras. Anais... Viçosa : Sociedade Brasileira de Zootecnia, 1992. 576p. p.149.

MARTINEZ, H.E.B. GARCIA, J.A da, SILVA, JF.C $\boldsymbol{e} \boldsymbol{t} \boldsymbol{a l}$. Influência do tratamento de rações contendo diferentes níveis de óleo de soja, com formaldeído, sobre a performance de novilhos zebus. Rev Soc Bras Zootec, Viçosa, v.10, n.4, p.735-756, 1981.

NRC (NATIONAL RESEARCH COUNCIL). Nutrent requeriments of beef catle. 6 ed. Washington : National Academy of Sciences, 1984. 90p. 
OBEID, J.A., GOMIDE, J.A. Resposta de novilhos zebus a aplicação de anabolizantes, alimentados com diferentes fontes de energia e de proteína. Rev Soc Bras Zootec, Viçosa, v.8, n.3, p.435-447, 1979.

PALMQUIST, D.L. Suplementação de lipídios para vacas em lactação. In: SIMPÓSIO SOBRE PRODUÇÃO ANIMAL, Piracicaba, São Paulo, 6, 1989, Piracicaba. Anais... Piracicaba : FEALQ, 1989. 165p. p.11-25

PILAR, R.C. Avaliação de diferentes fontes de volumoso (silagens) na alimentação de bovinos de corte em regime de confinamento. Santa Maria, 1993. 130p. Dissertação (Mestrado em Zootecnia) - Curso de Pós-graduação em Zootecnia, Universidade Federal de Santa Maria, 1993.

QUADROS, A.R.B. de, RESTLE, J. SANCHEZ, L.M.B. Desempenho em confinamento de bovinos de diferentes idades alimentados com diferentes fontes protéicas. In: REUNIÃO ANUAL DA SOC. BRAS. ZOOTEC., 27, 1990, Campinas. Anais... Viçosa : Sociedade Brasileira de Zootecnia, 1990. 813p. P.25.

RESTLE, J., ALVES FILHO, D.C. Confinamento de terneiros inteiros ou castrados de diferentes grupos genéticos. In: REUNIÃO ANUAL DA SOC. BRAS. ZOOTEC., 29, 1992 , Lavras. Anais... Viçosa : Sociedade Brasileira de Zootecnia, 1992. 576p. p.186.
SAS. Copyright by SAS Institut Inc. North Caroline, USA: Cary, 1990. 890p.

SILVA, A.G. da Soja na alimentação de bovinos leiteiros. In: SIMPÓSIO SOBRE PRODUÇÃO ANIMAL, 6, 1989, Piracicaba. Anais... Piracicaba : FEALQ, 1989. 165p. p.27.

TILLEY, L.M., TERRY, R.S.A. Two-stage technique for the "in vitro" digestion of forage crops. Journal of British Grassland Society Hurley, v.18, n.121, p.104-111, 1963.

TOWNSEND, M.R. Desempenho em confinamento de diferentes categorias animais e características de carcaça e da carne de novilhos e vacas. Santa Maria, 1991. 123p. Dissertação (Mestrado em Zootecnia) - Curso de Pósgraduação em Zootecnia, Universidade Federal de Santa Maria, 1991.

VELLOSO, L., LOBO, R.B. DUARTE, F.A.M. et al. Engorda em confinamento de bovinos integrantes de nove diferentes grupos genéticos. In: REUNIÃO ANUAL SOC. BRAS. ZOOTEC., 26, 1986, Campo Grande. Anais... Viçosa : Sociedade Brasileira de Zootecnia, 1986. 447p. p.125.

VIEIRA, P.F., SILVA, J.F.C. da, GARCIA, J.A. et al. Influência do formaldeído e da adição de óleo de soja sobre a digestibilidade de nutrientes em rações com farelo de soja para bezerros fistulados no abomaso. Rev Soc Bras Zootec, Viçosa, v.10, n.3, p.550-575, 1981.

Ciência Rural, v. 30, n. 3, 2000. 